\title{
MENSURAÇÃO DO COMPROMETIMENTO ORGANIZACIONAL EM REDES DE INDÚSTRIAS VITIVINÍCOLAS BRASILEIRAS
}

\author{
Denise Genari \\ denisegenari@hotmail.com \\ Universidade de Caxias do Sul - Caxias do Sul, RS / Brasil \\ Kadígia Faccin \\ kadigia@msn.com \\ Universidade de Caxias do Sul - Caxias do Sul, RS / Brasil \\ Janaína Macke \\ jmacke@terra.com.br \\ Universidade de Caxias do Sul - Caxias do Sul, RS / Brasil
}

Recebido em 10/11/2011

Aprovado em 27/11/2012

Disponibilizado em 01/08/2013

Avaliado pelo sistema double blind review

Revista Eletrônica de Administração

Editor: Luís Felipe Nascimento

ISSN 1413-2311 (versão on-line)

Editada pela Escola de Administração da Universidade Federal do Rio Grande do Sul.

Periodicidade: Quadrimestral

Sistema requerido: Adobe Acrobat Reader.

\section{RESUMO}

O tema comprometimento está relacionado com o sentimento de identificação do indivíduo com a organização, caracterizada pela convicção e aceitação dos valores e objetivos da mesma, e pelo desejo de permanecer como um membro da organização. Além disso, o comprometimento vincula-se com a criação de vantagens competitivas para as empresas, além de influenciar no comportamento e atitudes dos colaboradores. Neste sentido, este estudo tem como principal objetivo avaliar como o comprometimento se manifesta no ambiente interno de organizações em redes, através da mensuração do mesmo em indústrias vitivinícolas localizadas no Vale dos Vinhedos (RS/Brasil) e associadas às redes APROVALE e APROBELO. Para tanto, desenvolveu-se uma pesquisa descritiva, com caráter quantitativo, utilizando questionários auto-administrados como técnica de coleta de dados. Já para a análise dos resultados, foram utilizadas algumas técnicas estatísticas como análise descritiva, análise fatorial e análise de variância. Os principais resultados evidenciam a predominância da dimensão afetiva do comprometimento, que diz respeito aos sentimentos de orgulho e pertencimento à organização, o que pode ser explicado pelo destaque que a indústria vitivinícola brasileira vem recebendo e, também, pelas características de empresa familiar do contexto em estudo. Além disso, foram observadas diferenças significativas quanto às variáveis relacionadas ao grau de instrução, idade, tempo de empresa e área de atuação na empresa, especialmente em relação ao comprometimento instrumental. 
Mensuração do comprometimento organizacional em redes de indústrias vitivinícolas brasileiras

Palavras-Chave: Comprometimento Organizacional; Organizações em Rede; Indústria Vitivinícola.

\title{
MEASURING ORGANIZATIONAL COMMITMENT IN BRAZILIAN WINE INDUSTRY NETWORKS
}

\begin{abstract}
The organizational commitment is related to feeling of identification with the organization, characterized by the belief and acceptance of the company's values and goals, and the desire to remain as a member of the organization. Furthermore, the organizational commitment is linked to the creation of competitive advantage, as well as influencing the behavior and attitudes of employees. This study has as main objective to evaluate how organizational commitment manifests itself in the context of organizations into networks, in a sample of wine industries located in the Vinhedos Valley (southern Brazil) and members of APROVALE and APROBELO networks. We performed a descriptive and quantitative research, using self-administered questionnaires for data collection. We used statistical techniques as factor analysis, descriptive analysis and analysis of variance. The main results show the predominance of the affective dimension of commitment, which refers to feelings of pride and belonging to the organization, which can be explained by the recognition that the Brazilian wine industry has received, and also by the characteristics of the family businesses present in the context. In addition, there were significant differences in variables related to educational level, age, time in the company and area of expertise in the enterprise, especially in relation to continuance dimension of organizational commitment.
\end{abstract}

Keywords: Organizational Commitment; Network Organizations; Brazilian Wine Industry.

\section{EVALUACIÓN DEL COMPROMETIMIENTO ORGANIZACIONAL EN LAS REDES DE LAS INDUSTRIAS VITIVINÍCOLAS BRASILEÑAS}

\section{RESUMEN}

El tema comprometimiento está relacionado con el sentimiento de identificación del individuo con la organización, caracterizada por la convicción y aceptación de los valores y objetivos de la misma, y por el deseo de permanecer como un miembro de la organización. Además de eso, el comprometimiento se vincula a la creación de ventajas competitivas para las empresas, además de influir en el comportamiento y actitudes de los colaboradores. En esta dirección, el estudio tiene como principal objetivo evaluar como el comprometimiento se manifiesta en el ambiente interno de las organizaciones en redes, a través de la evaluación del mismo en industrias vitivinícolas ubicadas en el Vale dos Vinhedos (RS/Brasil) y asociadas a las redes APROVALE y APROBELO. Luego, se desarrolló una investigación descriptiva, con carácter cuantitativo, utilizando cuestionarios auto-administrados como técnica de recolecta de datos. Ya para el análisis de los resultados, fueron utilizadas algunas técnicas estadísticas como el análisis descriptivo, el análisis factorial y el análisis de variación. Los principales resultados ponen de manifiesto el predominio de la dimensión afectiva del comprometimiento, que se refiere a los sentimientos de orgullo y de pertenencia a la organización, lo que puede ser 
explicado por el destaque que la industria vitivinícola brasileña ha recibido y, también, por las características de empresa familiar del contexto en estudio. Además de eso, fueron observadas diferencias significativas en cuanto a las variables relacionadas al grado de instrucción, edad, tiempo de empresa y área de actuación en la empresa, especialmente en relación al comprometimiento instrumental.

Palabras Clave: Comprometimiento Organizacional; Organizaciones en Red; Industria Vitivinícola.

\section{INTRODUÇÃO}

O tema comprometimento organizacional vem obtendo cada vez mais destaque no cenário empresarial. O comprometimento no trabalho se refere à identificação do indivíduo com a organização, caracterizado pela convicção e aceitação dos valores e objetivos da mesma, acompanhado pelo desejo de permanecer como um membro e por realizar esforços em benefício da organização (MOWDAY et al., 1986).

Neste sentido, a importância do tema comprometimento é abordada por Bastos e Borges-Andrade (2002, p. 33), que descrevem que "o envolvimento ou comprometimento do trabalhador parece ser elemento crucial nas novas arquiteturas organizacionais emergentes". Este tema também se relaciona com a criação de vantagens competitivas para a organização (DESSLER, 1996) e com as atitudes e comportamentos dos funcionários de uma empresa (DIAS e DEL MAESTRO FILHO, 2008).

Diante deste contexto, realizar estudos sobre as manifestações do comprometimento em organizações pode contribuir para o entendimento de como este construto pode contribuir no aumento das vantagens anteriormente citadas.

Esta pesquisa objetivou avaliar como o comprometimento se manifesta no ambiente de organizações em redes. Este processo ocorreu através da realização de pesquisa em indústrias vitivinícolas gaúchas associadas à APROVALE e APROBELO, sendo que estas empresas serão descritas no decorrer do presente artigo.

\section{COMPROMETIMENTO ORGANIZACIONAL}

O conjunto de transformações visualizadas nos processos produtivos, na forma de organização do trabalho e nos padrões de gestão das sociedades industrializadas, impulsionadas pelas novas tecnologias em um contexto de crescente globalização da economia, justifica o crescente interesse de pesquisadores e administradores pelo tema 
Mensuração do comprometimento organizacional em redes de indústrias vitivinícolas brasileiras

comprometimento organizacional (BASTOS, 1996). O autor explica esta relação afirmando que:

(...) tais mudanças têm conduzido a experiências com novas arquiteturas organizacionais que apontam a importância de fatores individuais tais como interesse, motivação, responsabilidade, criatividade, participação, compromisso e envolvimento como elementos críticos na constituição de modelos organizacionais flexíveis e mais hábeis em lidar com as incertezas ambientais (BASTOS, 1996, p. 94).

A obtenção de níveis mais elevados de comprometimento dos funcionários é extremamente importante no atual mercado, no qual a qualidade e a satisfação dos clientes são chaves para o sucesso competitivo. Como consequência, as organizações buscam desenvolver novas estratégias que visam atender a essa necessidade (OSTERMAN, 2011).

O estudo do comprometimento nas organizações tem servido de base para a formação de políticas que buscam a qualidade, através do fortalecimento dos vínculos do trabalhador com seu próprio trabalho (MARTINS, 2003). Além disso, o comprometimento dos funcionários com a empresa pode tornar-se sua vantagem competitiva ${ }^{1}$, uma vez que a mesma não reside apenas em máquinas ou patentes, por exemplo, mas sim em pessoas capazes de inovar e investir em si mesmas para o progresso da organização (DESSLER, 1996).

Brito e Bastos (2001) afirmam que, diante das transições que marcam o mundo do trabalho e os processos organizacionais, pode-se apresentar dois argumentos que reforçam a importância de pesquisas sobre comprometimento organizacional. Inicialmente, parte-se do princípio de que qualquer processo organizativo necessita de relações de compromisso entre os atores envolvidos em torno das metas, missão e valores organizacionais. Além disso, o comprometimento pode ser considerado um fator que potencializa as possibilidades de as organizações enfrentarem, com êxito, as transições e turbulências existentes no mercado. Assim, segundo os autores, o comprometimento é considerado elemento estratégico para as organizações.

Convergindo com as ideias acima citadas, Fiorito et al. (2007) afirmam que muitas pesquisas abordam o comprometimento devido à crença de que o mesmo afeta diretamente a performance organizacional. Jafri (2010), em pesquisa recente realizada com executivos do

\footnotetext{
${ }^{1}$ Porter (1989) afirma que a vantagem competitiva surge quando uma empresa consegue criar valor para seus clientes e que este valor ultrapassa os custos de fabricação. $\mathrm{O}$ autor define valor como aquilo que os consumidores estão dispostos a pagar, sendo que o valor superior provém da oferta de preços mais baixos do que os da concorrência por benefícios equivalentes ou do fornecimento de benefícios únicos que compensem um preço mais alto.
} 
setor de varejo, demonstrou que o comprometimento (principalmente, o comprometimento afetivo, que será descrito no decorrer deste estudo) possui relação direta com a capacidade inovadora das empresas pesquisadas. Esta constatação reforça o vínculo existente entre o comprometimento e os resultados organizacionais.

Os crescentes estudos sobre comprometimento estão baseados no fato de que o mesmo pode afetar diversas atitudes e comportamentos importantes no contexto organizacional, como a assiduidade, intenção ou abandono efetivo da organização, pontualidade, atitudes frente às mudanças, desempenho individual, comportamentos de cidadania ou negligência e desempenho organizacional (DIAS e DEL MAESTRO FILHO, 2008). Por estes motivos, os autores destacam a crescente busca, entre os pesquisadores, em esclarecer as razões pelas quais os indivíduos desenvolvem laços psicológicos que caracterizam a ligação dos mesmos com a empresa onde atuam.

Assim, verifica-se que o comprometimento está diretamente relacionado à ampliação da consciência do indivíduo. Este processo ocorre na medida em que o mesmo não se contenta apenas com recompensas financeiras, mas sim com o desejo de conhecer melhor a si mesmo e a empresa, para poder participar efetivamente da vida organizacional (MACÊDO et al., 2005). Esta participação pode ser reforçada quando se percebe que o comprometimento está vinculado ao grau com que o indivíduo aceita e internaliza os valores e objetivos da empresa e toma consciência seu papel em termos de possibilidades de contribuição para o atendimento destes objetivos e valores (CHAHAL e MEHTA, 2011).

Reforçando a pluralidade de conceitos sobre comprometimento organizacional, Bandeira et al. (2000) afirmam que o termo foi definido com o objetivo de gerar diversas interpretações, consistindo em:

atitude ou orientação para a organização, que une a identidade da pessoa à empresa. Pode ser um fenômeno estrutural que ocorre como resultado de transações entre os atores organizacionais; ou um estado em que o indivíduo se torna ligado à organização por suas ações e crenças ou ainda a natureza do relacionamento de um membro com o sistema como um todo (BANDEIRA et al., 2000, p. 134).

Além disso, de acordo com Fiorito et al. (2007), o comprometimento apresenta três fatores característicos: forte crença nos objetivos e valores da organização, disponibilidade em exercer um esforço extra em nome da empresa e grande desejo de aderir e pertencer à mesma.

Ao abordar o conceito de comprometimento nas organizações, cabe destacar a variedade de definições e abordagens para o tema. Na Figura 1 destacam-se algumas destas REAd I Porto Alegre - Edição 75 - N 2 - maio/agosto 2013 - p. 351-383 
Mensuração do comprometimento organizacional em redes de indústrias vitivinícolas brasileiras

definições, bem como a evolução do tema, apresentados em revisão bibliográfica realizada por Yilmaz (2008) e Almeida (2009). 
Denise Genari, Kadígia Faccin \& Janaina Macke

Figura 1 - Conceitos de comprometimento organizacional

\begin{tabular}{|c|c|}
\hline Referência & Conceito \\
\hline Homan’s (1958) & $\begin{array}{l}\text { Base calculista de comprometimento, em que este será tanto maior quanto menor for a } \\
\text { percepção de mobilidade laboral do colaborador. }\end{array}$ \\
\hline Becker (1960) & $\begin{array}{l}\text { O comprometimento baseia-se numa noção de troca (teoria side bets), correspondendo } \\
\text { ao custo reconhecido em alterar os comportamentos que são considerados como linhas } \\
\text { constantes de atividade. }\end{array}$ \\
\hline Kantor (1968) & Desejo de dispender energia em prol de uma organização, à qual se é leal. \\
\hline Sheldon (1971) & $\begin{array}{l}\text { Identificação positiva com a organização e intenção de trabalhar em prol dos objetivos } \\
\text { por ela definidos. }\end{array}$ \\
\hline Alluto (1973) & $\begin{array}{l}\text { Falta de vontade em abandonar a organização, pela ponderação de possíveis aumentos } \\
\text { no salário, da possibilidade de progressão na carreira e dos laços de amizade com os } \\
\text { colegas de trabalho. }\end{array}$ \\
\hline Buchanan (1974) & $\begin{array}{l}\text { Ligação partidária e afetiva aos objetivos e valores da organização, ao seu papel dentro } \\
\text { da mesma e à organização enquanto entidade, pelo seu valor independente de } \\
\text { avaliações puramente instrumentais. }\end{array}$ \\
\hline Porter et al. (1974) & $\begin{array}{l}\text { Força de identificação e do envolvimento de um indivíduo a uma organização em } \\
\text { particular. }\end{array}$ \\
\hline Steers (1977) & Identificação e envolvimento com uma dada organização. \\
\hline $\begin{array}{l}\text { Mobley et al. } \\
\quad(1979)\end{array}$ & Resultado do contrato psicológico entre o indivíduo e a organização. \\
\hline Scholl (1981) & $\begin{array}{l}\text { Força estabilizadora que serve para manter o direcionamento do comportamento, } \\
\text { quando as expectativas sobre a organização não são preenchidas. }\end{array}$ \\
\hline $\begin{array}{l}\text { Michaels e Spector } \\
\quad(1982)\end{array}$ & $\begin{array}{l}\text { Processo pelo qual o indivíduo considera a sua relação e congruência de valores com a } \\
\text { organização, avaliando a pertinência da continuidade e permanência na mesma. }\end{array}$ \\
\hline Wiener (1982) & $\begin{array}{l}\text { Crença do colaborador em que está a assumir o comportamento "certo e moral", sendo } \\
\text { os valores o conjunto de regras internalizadas que visam atingir os objetivos da } \\
\text { organização. }\end{array}$ \\
\hline $\begin{array}{l}\text { Lee e Mowday } \\
\quad(1987)\end{array}$ & $\begin{array}{l}\text { Resposta afetiva resultante da avaliação da situação laboral que cria um laço com a } \\
\text { organização. }\end{array}$ \\
\hline Steel (1990) & Força relativa da identificação e envolvimento do colaborador com a organização. \\
\hline Pfeffer, 1994 & $\begin{array}{l}\text { Vontade do colaborador transmitir para o mercado uma imagem positiva da sua } \\
\text { organização (ajudando aos processos de recrutamento). }\end{array}$ \\
\hline $\begin{array}{l}\text { Iverson e Buttigieg } \\
\qquad(1999)\end{array}$ & Laço afetivo que representa o grau de lealdade sentida para com a organização. \\
\hline $\begin{array}{l}\text { Pengilly e Dowd } \\
\qquad(2000)\end{array}$ & $\begin{array}{l}\text { Totalidade das pressões normativas internas que conduzem a atuação no sentido da } \\
\text { prossecução dos objetivos organizacionais. }\end{array}$ \\
\hline
\end{tabular}


Mensuração do comprometimento organizacional em redes de indústrias vitivinícolas brasileiras

Continuação da Figura 1

\begin{tabular}{|c|c|}
\hline $\begin{array}{l}\text { Bishop e Scott, } \\
\quad 2000\end{array}$ & Predisposição do colaborador para ser orientado num dado curso de ação. \\
\hline $\begin{array}{l}\text { Allen e Meyer, } \\
\quad 2000\end{array}$ & $\begin{array}{l}\text { Laço psicológico que caracteriza a ligação do indivíduo à organização e reduz a } \\
\text { probabilidade de ele a abandonar. }\end{array}$ \\
\hline $\begin{array}{l}\text { Mc Donald e Makin } \\
\qquad(2000)\end{array}$ & $\begin{array}{l}\text { Comprometimento organizacional definido como um trato psicológico entre o } \\
\text { funcionário e a organização. }\end{array}$ \\
\hline $\begin{array}{c}\text { Meyer e } \\
\text { Herscovitch (2001) }\end{array}$ & $\begin{array}{l}\text { Força que liga o indivíduo a um curso de ação, com relevância para um ou mais } \\
\text { objetivos, enfatizando o curso de ação, mas descrevendo os objetivos finais. }\end{array}$ \\
\hline $\begin{array}{l}\text { Valentine et al. } \\
\qquad(2002)\end{array}$ & $\begin{array}{l}\text { Comprometimento organizacional é abordado como a inclinação dos interesses dos } \\
\text { trabalhadores e dos compromissos com a organização. }\end{array}$ \\
\hline Özsoy et & $\begin{array}{l}\text { Para os autores, o comprometimento organizacional está relacionado à uma maior } \\
\text { valorização, por parte dos funcionários de uma empresa, dos resultados da organização } \\
\text { em relação aos seus próprios benefícios (ou resultados). }\end{array}$ \\
\hline Ince e Gül (2005) & $\begin{array}{l}\text { De acordo com os autores, o comprometimento organizacional está relacionado à } \\
\text { fatores como aceitação e forte crença nos valores e objetivos da organização, além do } \\
\text { desenvolvimento de um trabalho mais intenso e entusiástico com a meta de criar } \\
\text { benefícios para a organização e continuar fazendo parte da mesma. }\end{array}$ \\
\hline Yilmaz (2008) & $\begin{array}{l}\text { Comprometimento organizacional pode ser definido como a adoção dos objetivos da } \\
\text { empresa, pelos seus funcionários, e o comprometimento dos mesmos com o } \\
\text { atendimento destes objetivos por parte da organização. }\end{array}$ \\
\hline
\end{tabular}

Fonte: Adaptado de Yilmaz (2008) e Almeida (2009).

Já Meyer e Allen (1991), em um estudo clássico sobre o tema, destacam que a visão mais comum relacionada ao comprometimento é que o mesmo se refere ao estado psicológico que caracteriza as relações dos funcionários com a organização e que implica na decisão de continuar fazendo parte da mesma. Além disso, os autores descrevem três componentes do comprometimento, também abordados por outros autores e apresentados no decorrer deste estudo:

a) comprometimento afetivo: relacionado ao envolvimento emocional do funcionário e à existência de identificação com a organização;

b) comprometimento instrumental: relacionado a um comprometimento percebido como custos associados por deixar a organização;

c) comprometimento normativo: relacionado ao sentimento de obrigação em permanecer na organização.

REAd I Porto Alegre - Edição 75 - N 2 - maio/agosto 2013 - p. 351-383 
Considerando a dimensão afetiva, os funcionários afetivamente comprometidos são mais motivados para contribuir com o desempenho da organização. Assim, a empresa apresenta um menor índice de turnover e absenteísmo, além de ocorrer a presença de comportamentos de cidadania organizacional (ORGAN e PAINE, 2000 apud REGO et al., 2007). O comprometimento afetivo tende a ser mais representativo na organização quando os funcionários percebem a congruência entre seus objetivos próprios e os da empresa, possuem confiança na organização e seus líderes, obtêm satisfação no trabalho e percebem um tratamento justo e socialmente responsável, por parte da empresa (REGO et al., 2007).

$\mathrm{Na}$ abordagem do comprometimento instrumental, Rego et al. (2007) afirmam que os funcionários provavelmente não sintam qualquer propensão a dar à organização mais do que aquilo a que estão obrigados. Neste sentido, poderão ocorrer atitudes negativas em relação à organização, como o aumento do absenteísmo e comportamentos retaliatórios. Além disso, esta dimensão se desenvolve quando o funcionário não tem alternativas de emprego em outras organizações ou percebe que, ao sair da empresa, perderá investimentos nela feitos.

No aspecto normativo do comprometimento é provável que os funcionários apresentem comportamentos relacionados a obrigações e deveres de lealdade para com a organização e, por isso, tendam a adotar comportamentos positivos. Este fenômeno poderá ocorrer por alguns motivos, como um sentimento de satisfação e apoio no trabalho, identificação com os valores da organização, confiança nos líderes e presença de políticas de 'recursos humanos' que valorizem os trabalhadores como pessoas e não apenas como recursos (REGO et al., 2007).

Apesar disso, o comprometimento afetivo tende a suscitar sentimentos de entusiasmo e envolvimento mais representativos, se comparado ao laço normativo. Logo, os resultados organizacionais positivos na dimensão afetiva tendem a ser mais notórios (REGO et al., 2007).

Ainda tratando sobre os múltiplos enfoques dados ao termo comprometimento, Bastos (1993) diz que o estudo sobre o tema pode diversificar-se de acordo com os diferentes objetos que podem ser considerados alvos deste vínculo do trabalhador. Neste sentido, o autor afirma que a organização, sindicatos, valores, profissão e o trabalho, por exemplo, podem constituir linhas de investigação próprias. Porém, existem, entre estas linhas, problemas comuns e a necessidade de integração das mesmas. 
Mensuração do comprometimento organizacional em redes de indústrias vitivinícolas brasileiras

Neste mesmo estudo, Bastos (1993) apresenta uma síntese das principais abordagens de comprometimento organizacional, conforme a Figura 2. Assim, o autor descreve que a diversidade de definições, com raízes em disciplinas como a sociologia, teoria das organizações e psicologia social contribuem para a compreensão do comportamento organizacional.

\begin{tabular}{|c|c|c|}
\hline Enfoque (rótulo) & Conceitos & Operacionalização construto \\
\hline $\begin{array}{l}\text { Autoridade no contexto } \\
\text { de trabalho }\end{array}$ & $\begin{array}{l}\text { - "Interesse de continuar no } \\
\text { emprego atual por entender a } \\
\text { legitimidade da relação de } \\
\text { autoridade-subordinação". } \\
\text { - O papel de subordinação envolve } \\
\text { códigos normativos sobre modos } \\
\text { corretos de dominação. }\end{array}$ & $\begin{array}{l}\text { - Medidas do julgamento do } \\
\text { indivíduo acerca da } \\
\text { probabilidade de deixar a } \\
\text { organização por outro emprego e } \\
\text { sob que condições. }\end{array}$ \\
\hline $\begin{array}{c}\text { Side-beats instrumental } \\
\text { calculativo }\end{array}$ & $\begin{array}{l}\text { - "Tendência de se engajar em } \\
\text { linhas consistentes de atividades } \\
\text { devido aos custos associados a agir } \\
\text { de forma diferente". } \\
\text { - "Mecanismo psicossocial que } \\
\text { envolve side-beats, trocas, } \\
\text { investimentos que limitam o raio } \\
\text { de ação posterior". }\end{array}$ & \multirow{3}{*}{$\begin{array}{l}\text { - Escalas de atitudes: } \\
\text { normalmente formato Likert } \\
\text { (itens positivos e negativos sobre } \\
\text { o conteúdo teórico mensurado). } \\
\text { Uso comum de análises fatoriais } \\
\text { para a validação do construto. }\end{array}$} \\
\hline Afetivo & $\begin{array}{l}\text { - “A força relativa da identificação } \\
\text { e envolvimento com uma } \\
\text { organização particular". } \\
\text { - Forte crença e aceitação dos } \\
\text { objetivos e valores. } \\
\text { - Desejo de esforçar-se pela } \\
\text { organização. } \\
\text { - Forte desejo de permanecer como } \\
\text { membro. }\end{array}$ & \\
\hline Normativo & $\begin{array}{l}\text { - "Totalidade de pressões } \\
\text { normativas internalizadas pelo } \\
\text { indivíduo para que se comporte } \\
\text { congruentemente com os objetivos } \\
\text { e interesses da organização". }\end{array}$ & \\
\hline Comportamental & $\begin{array}{l}\text { - "Um estado de ser em que as } \\
\text { ações determinam crenças que } \\
\text { sustentam a atividade e seu próprio } \\
\text { envolvimento". }\end{array}$ & $\begin{array}{l}\text { - Tempo na organização. } \\
\text { - Desempenho. } \\
\text { - Comportamentos extrapapéis. }\end{array}$ \\
\hline
\end{tabular}

Figura 2 - Abordagens conceituais do comprometimento organizacional Fonte: Adaptado de Bastos (1993, p. 55). 
Outra abordagem importante discutida por Bastos (1993) é a apresentação dos antecedentes, correlatos e consequentes do comprometimento organizacional, conforme descrito a seguir e exemplificado na Figura 3:

a) antecedentes: se apresentam através de quatro conjuntos de variáveis citadas nas pesquisas de Mowday (1982). Baseiam-se nas características pessoais, nas características dos trabalhadores, experiências no trabalho e "estados" do papel;

b) correlatos: representados por variáveis que não podem ser consideradas nem antecedentes e nem consequentes do comprometimento. Além disso, se apresentam em construtos atitudinais e motivacionais utilizados na pesquisa organizacional;

c) consequentes: considerados consequências do comprometimento dos funcionários no trabalho, se apresentam principalmente na decisão, por parte do mesmo, de permanecer ou abandonar a organização e no desempenho no trabalho.

\begin{tabular}{|c|c|c|}
\hline \multirow{5}{*}{ Antecedentes } & Características pessoais & $\begin{array}{l}\text { Idade, sexo, educação, tempo de organização, } \\
\text { percepção competência pessoal, ética no trabalho, } \\
\text { nível ocupacional, salário. }\end{array}$ \\
\hline & Características do trabalho & $\begin{array}{l}\text { Variedade de habilidades, autonomia, inovação, } \\
\text { "escopo". }\end{array}$ \\
\hline & Relações líder-grupo & $\begin{array}{l}\text { Coesão do grupo, interdependência de tarefas, } \\
\text { liderança participativa. }\end{array}$ \\
\hline & Características organizacionais & Tamanho, centralização. \\
\hline & Características do "papel” & Ambiguidade, conflito, sobrecarga. \\
\hline \multirow[t]{2}{*}{ Correlatos } & Diversos & $\begin{array}{l}\text { Motivação geral e interna, envolvimento com } \\
\text { trabalho, stress, comprometimento relacionado } \\
\text { com a ocupação e sindicato. }\end{array}$ \\
\hline & Satisfação no trabalho & $\begin{array}{l}\text { Geral, intrínseca, extrínseca, supervisão, colegas } \\
\text { (grupo), promoções, pagamentos, trabalho em si. }\end{array}$ \\
\hline \multirow[b]{2}{*}{ Consequentes } & Desempenho & Avaliação por outros, avaliação do produto. \\
\hline & Diversos & $\begin{array}{l}\text { Percepção de alternativas de trabalho, intenção de } \\
\text { procurar novo trabalho, intenção de sair, } \\
\text { comparecimento, atrasos, rotatividade. }\end{array}$ \\
\hline
\end{tabular}

Figura 3 - Antecedentes, correlatos e consequentes do comprometimento organizacional Fonte: Adaptado de Bastos (1993, p. 61). 
Mensuração do comprometimento organizacional em redes de indústrias vitivinícolas brasileiras

De acordo a revisão bibliográfica realizada para a elaboração desta pesquisa, verificou-se a existência de diversos estudos sobre comprometimento organizacional e diferentes possibilidades de medição.

Estes trabalhos apresentam, na sua grande maioria, uma estratégia metodológica que prioriza a análise de dados quantitativos, com uso de análises estatísticas. Além disso, o comprometimento é mensurado através de escalas, no geral do tipo Likert, com níveis elevados de confiabilidade (BASTOS, 1996).

Segundo Medeiros et al. (2003), as pesquisas sobre comprometimento tiveram, durante muito tempo, um enfoque na dimensão afetiva, baseada em trabalhos desenvolvidos por Mowday et al. (1982). Estas pesquisas tiveram início na década de 70 e culminaram com a validação de um instrumento para medir comprometimento organizacional denominado Organizational Commitment Questionare (OCQ).

Este instrumento, por sua vez, foi validado a partir de um banco de dados de 2.563 empregados e obteve um índice de consistência interna de $\alpha=0,90$. A escala utilizada no instrumento é formada por 15 indicadores de comprometimento, possuindo uma versão reduzida com nove itens. A escala OCQ é do tipo Likert, podendo ser utilizada com 7 ou 5 pontos, variando de discordo totalmente a concordo totalmente. Embora a escala original possua 7 pontos, alguns estudos a utilizam com apenas 5 (MEDEIROS et al., 2003).

Neste sentido, pode-se destacar alguns estudos que relacionam o comprometimento nas organizações com outros elementos do contexto empresarial e utilizam o questionário para medir comprometimento organizacional desenvolvido por Mowday et al. (1982):

a) estudo que analisou os temas comprometimento com a organização, carreira e sindicatos, através da identificação de oito padrões de comprometimento em uma amostra de 1.029 trabalhadores de 20 empresas distintas (BASTOS e BORGESANDRADE, 2002);

b) estudo que buscou verificar quais as relações existentes entre o comprometimento organizacional, as práticas de recursos humanos e as características das empresas pesquisadas (FIORITO et al., 2007);

c) artigo que objetivou identificar a intensidade, natureza e antecedentes do comprometimento organizacional de servidores técnicos administrativos de uma universidade estadual localizada na Bahia (LEITE, 2007); 
d) pesquisa que buscou relacionar o comprometimento organizacional com fatores estressantes no trabalho e identidade social. Os resultados apontaram que o fator de estresse: relações sociais de trabalho apresentou uma correlação negativa com o comprometimento organizacional. Além disso, foi confirmada a hipótese de uma relação significativa entre a identidade social e o comprometimento organizacional (MENDONZA, 2007).

Outros estudos, como os descritos a seguir, são realizados com base nas dimensões afetiva, instrumental e normativa descritas por Meyer e Allen (1991). Segundo Medeiros et al. (2003), as escalas desenvolvidas pelos autores apresentam duas espécies: uma escala com 24 itens e outra reduzida a 18 itens. Além disso, utiliza-se uma escala de medição tipo Likert, onde um terço dos indicadores se relaciona ao comprometimento afetivo, e os demais ao comprometimento instrumental e normativo:

a) pesquisa que analisa a relação dos diferentes tipos de cultura organizacional de empresas hoteleiras com a natureza do vínculo estabelecido entre indivíduo e organização (NAVES e DELA COLETA, 2003);

b) pesquisa que objetivou comparar o grau de comprometimento entre funcionários terceirizados e efetivos de uma empresa de telefonia, localizada na região Sul do Brasil. No resultado, verificou-se uma diferença significativa no grau de comprometimento relacionado aos dois tipos de público-alvo acima descritos (SOLDI e ZANELLI, 2006);

c) estudo que investigou a relação entre valores organizacionais e comprometimento organizacional, a partir de uma pesquisa com funcionários de empresa siderúrgicas de Minas Gerais (DIAS e DEL MAESTRO FILHO, 2008);

d) pesquisa realizada em diversas organizações do setor público da Coreia, que procurou estabelecer quais são as relações existentes entre o comprometimento, os laços psicológicos do trabalhador com a empresa e a cultura de aprendizagem na organização (JOO e SHIM, 2010);

e) estudo realizado em organizações públicas localizadas na Índia, com a participação de gestores, verificando as relações existentes entre o tempo de empresa e a categoria profissional ocupada (executivo, técnico e administrativo) com os níveis de comprometimento e satisfação com o trabalho (NATARAJAN e NAGAR, 2011).

REAd I Porto Alegre - Edição 75 - Nº 2 - maio/agosto 2013 - p. 351-383 
Mensuração do comprometimento organizacional em redes de indústrias vitivinícolas brasileiras

Além das pesquisas acima descritas, destaca-se um estudo realizado por Rego et al. (2007), que foi utilizado como referência para a realização deste trabalho. Estes autores desenvolveram um estudo focando a espiritualidade nas organizações através da abordagem de cinco dimensões: sentido de comunidade, alinhamento do indivíduo com os valores da organização, sentido de préstimo à comunidade, alegria no trabalho e oportunidades para a vida interior. Posteriormente, estas mesmas dimensões foram vinculadas ao comprometimento organizacional.

A pesquisa foi realizada em uma amostra de 361 indivíduos de 154 organizações. Como resultado, os autores afirmam que as dimensões de espiritualidade explicam $48 \%, 16 \%$ e $7 \%$ de variância, respectivamente, do comprometimento afetivo, do normativo e do instrumental. Assim, sugerem que as pessoas, quando experimentam mais forte sentido de espiritualidade no trabalho, denotam mais elevados laços afetivos e normativos, enquanto os laços instrumentais mostram-se mais fracos.

Os autores, nesta pesquisa, realizaram a mensuração do comprometimento organizacional por meio de um questionário contendo 14 itens. Este instrumento foi desenvolvido Rego e Souto (2002, 2004), a partir da literatura e de trabalho próprio, sendo que o mesmo foi validado em Portugal e no Brasil. Este instrumento aborda as dimensões afetiva, normativa e instrumental do comprometimento organizacional e utiliza uma escala de sete pontos, onde " 1 " representa a sentença "A afirmação não se aplica rigorosamente a mim" e "7" descreve "A afirmação aplica-se completamente".

A Tabela 1 apresenta a análise fatorial confirmatória do modelo, sendo que, de acordo com os autores, para melhorar os índices de ajustamento, e atendendo aos índices de modificação e aos resíduos estandardizados, foram removidos três itens do questionário original. 
Tabela 1 - Comprometimento organizacional - análise fatorial confirmatória

\begin{tabular}{|c|c|}
\hline Comprometimento afetivo & $\mathbf{0 , 8 5 *}$ \\
\hline Tenho orgulho em dizer a outras pessoas que faço parte desta organização & 0,71 \\
\hline Tenho uma forte ligação de simpatia por esta organização & 0,90 \\
\hline Sinto-me "parte da família" da minha organização & 0,84 \\
\hline Comprometimento normativo & $0,76 *$ \\
\hline $\begin{array}{l}\text { Mesmo que isso me trouxesse vantagens, sinto que não deveria abandonar a minha } \\
\text { organização agora }\end{array}$ & 0,66 \\
\hline $\begin{array}{l}\text { Não deixaria a minha organização agora porque sinto obrigações para com as pessoas que } \\
\text { aqui trabalham }\end{array}$ & 0,79 \\
\hline $\begin{array}{l}\text { Sinto que, se recebesse uma oferta de melhor emprego, não seria correto deixar a minha } \\
\text { organização }\end{array}$ & 0,73 \\
\hline Comprometimento instrumental & $0,86 *$ \\
\hline $\begin{array}{l}\text { Mantenho-me nesta organização porque sinto que não conseguiria facilmente entrar noutra } \\
\text { organização }\end{array}$ & 0,69 \\
\hline Continuo nesta organização porque, se saísse, teria que fazer grandes sacrifícios pessoais & 0,64 \\
\hline Sinto que tenho poucas alternativas de emprego se deixar esta organização & 0,80 \\
\hline $\begin{array}{l}\text { Mantenho-me nesta organização porque sinto que tenho poucas oportunidades noutras } \\
\text { organizações }\end{array}$ & 0,89 \\
\hline Não abandono esta organização devido às perdas que me prejudicariam & 0,69 \\
\hline
\end{tabular}

Fonte: Adaptado de Rego et al. (2007, p. 10).

Com o objetivo de estudar o comprometimento organizacional, utilizou-se o instrumento para medição do conceito acima descrito, não sendo abordado, nesta pesquisa, o construto da espiritualidade organizacional.

\section{MÉTODO DE PESQUISA}

O presente estudo, de caráter descritivo, tem como objetivo principal verificar como o comprometimento se manifesta no ambiente interno de organizações em redes. Para isso, foram analisadas as variáveis que influenciam na criação do comprometimento organizacional 
Mensuração do comprometimento organizacional em redes de indústrias vitivinícolas brasileiras

e foi realizado um comparativo das principais características do perfil dos respondentes com as manifestações deste construto.

A pesquisa foi realizada com funcionários das indústrias vitivinícolas associadas à APROVALE (Associação de Produtores de Vinhos Finos do Vale dos Vinhedos) e à APROBELO (Associação de Produtores de Vinho de Monte Belo do Sul) e situadas no Vale dos Vinhedos (RS/Brasil). Esta região, colonizada por imigrantes italianos em 1876 (DALCIN, 2008), está localizada entre os municípios de Bento Gonçalves, Monte Belo do Sul e Garibaldi e é referência no cultivo de videiras e produção de vinhos, além de ser considerada como um importante polo turístico.

Um marco para o desenvolvimento da região acima citada foi a criação das associações de produtores de uvas e vinhos. A APROVALE, fundada em 1995, para atender às exigências legais para obtenção da indicação geográfica dos vinhos produzidos na região, conta com 31 vitivinícolas associadas e 28 associados não produtores de vinho, entre hotéis, pousadas, restaurantes, artesanatos, queijarias e outros (APROVALE, 2009).

Já a APROBELO, criada no ano de 2003, é composta por 12 vitivinícolas e tem como objetivos alavancar a qualidade nos processos de cultivo de uvas, especialmente no que tange a condução e o manejo das videiras, além de todas as etapas do processo de elaboração de vinhos e espumantes. Além disso, a entidade atua em um projeto de elaboração de vinhos e espumantes de qualidade com origem controlada, visando à certificação de indicação de procedência (APROBELO, 2009).

Utilizando a técnica de amostragem estratificada, foram distribuídos questionários auto-administrados para os funcionários das indústrias acima citadas. Foram distribuídos 280 questionários e obteve-se um retorno de 200 respondentes.

Após a revisão bibliográfica, fundamentada principalmente no estudo de Rego et. al. (2007), construiu-se o instrumento de pesquisa, subdividido em duas partes distintas.

O primeiro bloco é constituído por 11 itens que se relacionam às dimensões afetiva, instrumental e normativa do comprometimento organizacional, apresentados em forma de afirmativas. Os participantes responderam se a afirmação se aplicava ou não a sua realidade, com utilização de uma escala Likert de sete pontos, onde "1" representa "A afirmação não se aplica rigorosamente a mim" e "7" representa "A afirmação aplica-se completamente".

Já a segunda parte do instrumento apresenta um conjunto de questões de informações gerais sobre o respondente, como gênero, idade, grau de instrução, características de moradia, renda, tempo de empresa e outros. 
Após a coleta dos dados, realizou-se, para atender aos objetivos do estudo, a análise descritiva, análise fatorial e análise de variância, com a utilização do software SPSS (Statistical Package of Social Science), versão 17.0.

\section{RESULTADOS DA PESQUISA}

Nesta sessão serão descritos os principais resultados do estudo, através da aplicação da análise descritiva, análise fatorial e análise de variância.

\subsection{Análise descritiva e análise fatorial}

Inicialmente, as respostas dos 200 pesquisados foram submetidas à análise descritiva, sendo que a amostra pesquisada apresentou as seguintes características:

a) equilíbrio entre o gênero masculino e feminino, sendo que 50,8\% da amostra era composta por homens e 49,2\% por mulheres;

b) em relação à idade, $57,4 \%$ possui até 35 anos;

c) a escolaridade dos respondentes concentrou-se principalmente nos seguintes níveis: ensino fundamental incompleto $(18,8 \%)$, ensino médio completo $(20,9 \%)$ e graduação incompleta $(23,6 \%)$;

d) $82,6 \%$ são moradores da cidade de Bento Gonçalves e 12,1\% da amostra reside na cidade de Monte Belo do Sul, que sediam a APROVALE e a APROBELO, respectivamente;

e) 50,5\% moram no mesmo bairro há mais de 15 anos;

f) $72,4 \%$ residem em local próprio;

g) $34,2 \%$ dos entrevistados moram com cônjuges e crianças e apenas 7,4\% moram sozinhos;

h) $34,7 \%$ possuem filhos menores de 18 anos.

Ao abordar alguns aspectos profissionais, os pesquisados apresentaram as seguintes características, de acordo com a análise descritiva:

a) $30,9 \%$ da amostra possui vínculo de trabalho com a empresa há menos de um ano. Porém, 38,2\% dos pesquisados atua na organização há mais de 6 anos;

REAd I Porto Alegre - Edição 75 - Nº 2 - maio/agosto 2013 - p. 351-383 
Mensuração do comprometimento organizacional em redes de indústrias vitivinícolas brasileiras

b) $53,2 \%$ dos respondentes atua na área produtiva das vitivinícolas;

c) em relação à renda mensal, 37,7\% dos respondentes percebem uma remuneração que varia de $\mathrm{R} \$ 501,00$ a $\mathrm{R} \$ 999,00$, enquanto $27,2 \%$ possuem um salário entre $\mathrm{R} \$ 1.000,00$ e $\mathrm{R} \$ 1.499,00$;

d) embora as organizações pesquisadas sejam empresas familiares, apenas $12 \%$ dos funcionários pesquisados possuem parentesco com o(s) fundador(es) das empresas estudadas.

$\mathrm{Na}$ sequência, buscou-se analisar e medir as dimensões do comprometimento organizacional no contexto das indústrias vitivinícolas associadas à APROVALE e à APROBELO.

Levando-se em consideração que o comprometimento diz respeito à identificação do indivíduo com a organização, aceitação dos seus valores e objetivos e desejo de aderir e pertencer à mesma, é de extrema importância identificar quais dimensões se apresentam de maneira mais expressiva neste construto. Além disso, esta identificação se torna relevante uma vez que o comprometimento organizacional está vinculado à capacidade de progresso e resultados otimizados por parte das empresas (DESSLER, 1996; FIORITO et al., 2007).

Neste sentido, o primeiro bloco do instrumento de pesquisa apresentou questões utilizadas em estudo elaborado por Rego et al. (2007), com uma escala Likert de 7 pontos, para a medição do comprometimento organizacional. Através da aplicação do mesmo aos 200 entrevistados, obteve-se, pela análise descritiva, médias que variaram entre 2,66 e 5,70, com desvio-padrão entre 1,622 e 2,273.

Também foram obtidos dados que serviram de base para a realização de análise fatorial. Assim, as respostas da pesquisa foram submetidas à análise fatorial do tipo PCA (Principal Component Analysis), com rotação varimax e tratamento pairwise. Na análise dos questionários foram identificados poucos casos de respostas em branco (missing values).

Além disso, a fatorabilidade dos dados foi verificada através do índice Kaiser-MeyerOlkin (KMO), com resultado de 0,809 e do teste de esfericidade de Barlett, que apresentou uma significância de 0,000 . 
Também, com o objetivo de analisar a consistência interna das variáveis, realizou-se a medição do Alpha de Cronbach para as 11 questões sobre comprometimento organizacional, obtendo-se um resultado de 0,777 , o que representa um bom índice de consistência interna.

Logo, através da análise fatorial realizada, foram identificados os mesmos fatores referidos na pesquisa original realizada por Rego et al. (2007), em Portugal, destacando as dimensões de comprometimento afetivo, normativo e instrumental. Paralelamente, com o intuito de verificar a consistência das variáveis de cada fator, foram calculados os valores para o Alpha de Cronbach, apresentados na Tabela 2. Também calculou-se a variância explicada para o construto, que corresponde a $70,84 \%$.

Além das cargas fatoriais, realizou-se, na sumarização dos dados, a verificação das médias e correlações das variáveis com os fatores afetivo, normativo e instrumental do comprometimento organizacional. 
Mensuração do comprometimento organizacional em redes de indústrias vitivinícolas brasileiras

Tabela 2 - Comprometimento organizacional - análise fatorial com base na pesquisa

\begin{tabular}{|c|c|c|c|c|}
\hline Fator & Elementos do fator & $\begin{array}{l}\text { Média da } \\
\text { variável }\end{array}$ & Carga & $\begin{array}{l}\text { Correlação } \\
\text { com o fator }\end{array}$ \\
\hline \multirow{5}{*}{$\begin{array}{l}\text { Comprometimento } \\
\text { instrumental }\end{array}$} & $\begin{array}{l}\text { X } 45 \text { - Sinto que tenho poucas } \\
\text { alternativas de emprego se deixar } \\
\text { esta organização }\end{array}$ & 2,71 & 0,902 & 0,825 \\
\hline & $\begin{array}{l}\text { X } 46 \text { - Mantenho-me nesta } \\
\text { organização porque sinto que tenho } \\
\text { poucas oportunidades noutras } \\
\text { organizações }\end{array}$ & 2,66 & 0,887 & 0,805 \\
\hline & $\begin{array}{l}\text { X } 44 \text { - Continuo nesta organização } \\
\text { porque, se saísse, teria que fazer } \\
\text { grandes sacrifícios pessoais }\end{array}$ & 2,83 & 0,827 & 0,719 \\
\hline & $\begin{array}{l}\text { X } 43 \text { - Mantenho-me nesta } \\
\text { organização porque sinto que não } \\
\text { conseguiria facilmente entrar noutra } \\
\text { organização }\end{array}$ & 3,00 & 0,803 & 0,696 \\
\hline & $\begin{array}{l}\text { X } 47 \text { - Não abandono esta } \\
\text { organização devido às perdas que me } \\
\text { prejudicariam }\end{array}$ & 3,46 & 0,732 & 0,585 \\
\hline \multirow{3}{*}{$\begin{array}{c}\text { Comprometimento } \\
\text { afetivo }\end{array}$} & $\begin{array}{l}\text { X } 39 \text { - Sinto-me "parte da família" } \\
\text { da minha organização }\end{array}$ & 5,45 & 0,797 & 0,674 \\
\hline & $\begin{array}{l}\text { X } 38 \text { - Tenho uma forte ligação de } \\
\text { simpatia por esta organização }\end{array}$ & 5,49 & 0,818 & 0,662 \\
\hline & $\begin{array}{l}\text { X } 37 \text { - Tenho orgulho em dizer a } \\
\text { outras pessoas que faço parte desta } \\
\text { organização }\end{array}$ & 5,70 & 0,834 & 0,645 \\
\hline \multirow{3}{*}{$\begin{array}{c}\text { Comprometimento } \\
\text { normativo }\end{array}$} & $\begin{array}{l}\text { X } 40 \text { - Mesmo que isso me trouxesse } \\
\text { vantagens, sinto que não deveria } \\
\text { abandonar a minha organização } \\
\text { agora }\end{array}$ & 5,00 & 0,679 & 0,579 \\
\hline & $\begin{array}{l}\text { X } 41 \text { - Não deixaria a minha } \\
\text { organização agora porque sinto } \\
\text { obrigações para com as pessoas que } \\
\text { aqui trabalham }\end{array}$ & 4,75 & 0,643 & 0,563 \\
\hline & $\begin{array}{l}\text { X } 42 \text { - Sinto que, se recebesse uma } \\
\text { oferta de melhor emprego, não seria } \\
\text { correto deixar a minha organização }\end{array}$ & 4,06 & 0,867 & 0,485 \\
\hline
\end{tabular}

* Alfas de Cronbach do fator

Fonte: Dados compilados a partir do presente estudo. 
Assim como no estudo original elaborado por Rego et al. (2007), as variáveis relacionadas à dimensão do comprometimento afetivo apresentaram as maiores médias. Esta dimensão do comprometimento organizacional está vinculada à identificação do trabalhador com os objetivos e valores da empresa, ao desejo de permanecer como membro ativo da organização e de contribuir e dar energia para a empresa, além de apresentar sentimentos como lealdade, pertencimento, orgulho e afiliação.

Neste sentido, pode-se vincular a maior representatividade desta dimensão, no contexto da pesquisa, a algumas características regionais e empresariais.

Inicialmente, destaca-se a representatividade da variável deste fator que apresentou maior média (5,7): "tenho orgulho em dizer a outras pessoas que faço parte desta organização". Neste sentido, pode-se relacionar este fato ao crescente desenvolvimento e reconhecimento da região do Vale dos Vinhedos, destacando cada vez mais as indústrias vitivinícolas ali localizadas. Além disso, a atividade vitivinícola na Serra Gaúcha é extremamente valorizada, uma vez que a região é conhecida, nacional e internacionalmente, como um dos maiores pólos produtores de vinhos e vem se destacando nas atividades relacionadas ao enoturismo ${ }^{2}$ e à enogastronomia ${ }^{3}$.

Neste sentido, pode-se destacar que a região possui diversas cantinas e empreendimentos destinados aos turistas, onde o visitante tem a oportunidade de conhecer os processos de cultivo das vides, a elaboração de vinhos e participar de rituais de degustação (DALCIN, 2008). Logo, esta estrutura alavanca o reconhecimento da região como um emergente pólo turístico, sendo que este fato pode promover o sentimento de orgulho, por parte dos funcionários, em fazer parte destas organizações.

Já a variável "sinto-me "parte da família' da minha organização" pode ser explicada pelo fato das empresas pesquisadas apresentarem características de empresas familiares que, consequentemente, se refletem na forma de gestão da organização.

Bernhoeft (1989) corrobora com esta ideia afirmando que uma empresa familiar possui sua origem e sua história ligadas a uma família ou então, mantém membros da família

\footnotetext{
${ }^{2} \mathrm{O}$ enoturismo representa um segmento de atividade turística que se fundamenta no deslocamento de pessoas motivadas pela busca de atividades relacionadas ao vinho, como os aromas, a paisagem, a gastronomia e a cultura das localidades que elaboram a bebida (CIC BG, 2009).

${ }^{3} \mathrm{O}$ conceito de enogastronomia envolve a escolha pormenorizada de vinhos, a partir de suas características gustativas, para acompanhar pratos elaborados das culinárias tradicional, regional e criativa, ressaltando suas características e criando um conjunto sensorial (ACADEMIA DO VINHO, 2010).
} 
Mensuração do comprometimento organizacional em redes de indústrias vitivinícolas brasileiras

na administração do negócio. As principais características deste tipo de organização, segundo o autor, são a valorização da confiança mútua, laços afetivos extremamente fortes influenciando os comportamentos, valorização da antiguidade em relação à eficácia ou competência, exigência de dedicação e expectativa de fidelidade.

Logo, as características acima citadas podem reforçar o sentimento de pertencimento dos colaboradores a este tipo de organização, justificando o resultado encontrado na pesquisa.

Dando continuidade à análise do comprometimento afetivo, buscou-se vincular os resultados obtidos na pesquisa com algumas características organizacionais da região. Alguns autores, como Bastos (1993), destacam que os níveis de absenteísmo e rotatividade podem ser consequência dos níveis de comprometimento. Neste sentido, funcionários afetivamente comprometidos serão mais motivados para contribuir com o desempenho da organização, apresentando um menor índice de rotatividade e absenteísmo (ORGAN e PAINE, 2000 apud REGO et al., 2007).

Assim, buscou-se verificar estes índices nas indústrias pesquisadas e a existência de alguma pesquisa setorial neste sentido. Porém, nenhuma entidade de classe, vinculada às indústrias vitivinícolas, realizou, recentemente, este tipo de levantamento de dados. Além disso, devido ao pequeno porte da maioria das empresas pesquisadas, não ocorre, nas mesmas, a medição deste tipo de indicador. Assim, contatou-se as quatro maiores vitivinícolas (em número de funcionários) da cidade de Bento Gonçalves e obteve-se os resultados apresentados na Tabela 3, a seguir. Das quatro empresas vitivinícolas investigadas, três são associadas à APROVALE e estão incluídas na amostra do presente estudo.

Tabela 3 - Indicadores de absenteísmo e rotatividade na indústria vitivinícola

\begin{tabular}{c|c|c}
\hline Empresas & Absenteísmo (\%)* & Rotatividade (\%)* $^{*}$ \\
\hline Empresa A & 1,30 & 2,10 \\
\hline Empresa B & 2,24 & 4,09 \\
\hline Empresa C & 1,98 & 1,28 \\
\hline Empresa D & 1,74 & 2,47 \\
\hline Média geral & $\mathbf{1 , 8 2}$ & $\mathbf{2 , 4 9}$ \\
\hline \multicolumn{3}{c}{ * Média referente ao ano de 2009. } \\
\hline
\end{tabular}

Fonte: Dados compilados a partir de pesquisa realizada pela autora. 
Com o objetivo de comparar os indicadores de rotatividade e absenteísmo apresentados na Tabela 3, realizou-se uma pesquisa destes mesmos índices em algumas indústrias moveleiras e metalúrgicas localizadas na cidade de Bento Gonçalves (Tabela 4), buscando elencar as maiores empresas destes segmentos por número de funcionários.

Tabela 4 - Indicadores de absenteísmo e rotatividade na indústria moveleira e metalúrgica

\begin{tabular}{c|c|c}
\hline Empresas & Absenteísmo (\%)* & Rotatividade (\%)* $^{*}$ \\
\hline Empresa A & 1,98 & 3,60 \\
\hline Empresa B & 1,45 & 2,80 \\
\hline Empresa C & 1,62 & 2,45 \\
\hline Empresa D & 1,79 & 6,81 \\
\hline Empresa E & 3,35 & 5,59 \\
\hline Média geral & $\mathbf{2 , 0 4}$ & $\mathbf{4 , 2 5}$ \\
\hline \multicolumn{3}{|c}{ * Média referente ao ano de 2009. }
\end{tabular}

Fonte: Dados compilados a partir de pesquisa realizada pela autora.

A escolha destes segmentos para a comparação de indicadores se deu, principalmente, pela representatividade dos mesmos na geração de empregos na região. O segmento metalmecânico compreende $20,82 \%$ do número de indústrias do município, gerando 4.500 empregos diretos e, aproximadamente, 20.000 empregos indiretos. Já o segmento moveleiro representa $19,95 \%$ do total de indústrias da cidade de Bento Gonçalves, gerando em torno de seis mil empregos diretos e indiretos. Por fim, pode-se destacar a posição da indústria vitivinícola no contexto do município. Este segmento representa, atualmente, 5,15\% do total de indústrias de Bento Gonçalves (CIC BG, 2009).

Através dos indicadores apresentados nas Tabelas 3 e 4 é possível verificar que as indústrias vitivinícolas pesquisadas apresentam menores índices de absenteísmo e rotatividade, quando comparadas às indústrias metalúrgicas e moveleiras. Esta constatação reforça a importância do desempenho do comprometimento afetivo para a manutenção destes índices, uma vez que as indústrias vitivinícolas abordadas nesta pesquisa apresentaram alto desempenho nesta dimensão (média do fator igual a 5,5).

Embora não existam, atualmente, pesquisas que verifiquem as manifestações sobre comprometimento organizacional nas indústrias metalúrgicas e moveleiras de Bento Gonçalves, considerou-se relevante realizar os comparativos acima descritos, pela representatividade destas empresas. Além disso, estas organizações acabam "concorrendo" 
Mensuração do comprometimento organizacional em redes de indústrias vitivinícolas brasileiras

entre si pela atração e retenção de mão-de-obra, uma vez que, atualmente, existe, de modo geral, uma dificuldade de obtenção de recursos humanos na região.

Após a análise dos escores encontrados na dimensão afetiva do comprometimento, buscou-se compreender o resultado das demais dimensões.

Assim, ao analisar as dimensões instrumental e normativa do comprometimento, verificou-se que as mesmas obtiveram menores escores. Em estudos anteriores, Rego e Souto (2004) verificaram que o comprometimento afetivo (que apresentou maiores médias) possui a tendência de associar-se positivamente com o normativo (média do fator igual a 4,60) e negativamente com o instrumental, que apresentou a menor média entre os fatores $(2,93)$.

Neste sentido, destaca-se que o comprometimento instrumental diz respeito a fatores externos sobre os quais o indivíduo tem pouco poder de ação. Assim, o colaborador adere às determinações da organização (comprometimento instrumental), sem necessariamente compartilhar dos mesmos valores e objetivos da empresa (comprometimento afetivo). Considera-se relevante destacar, conforme Figura 4, os antecedentes das dimensões do comprometimento organizacional, uma vez que os mesmos se relacionam com os resultados aqui descritos.

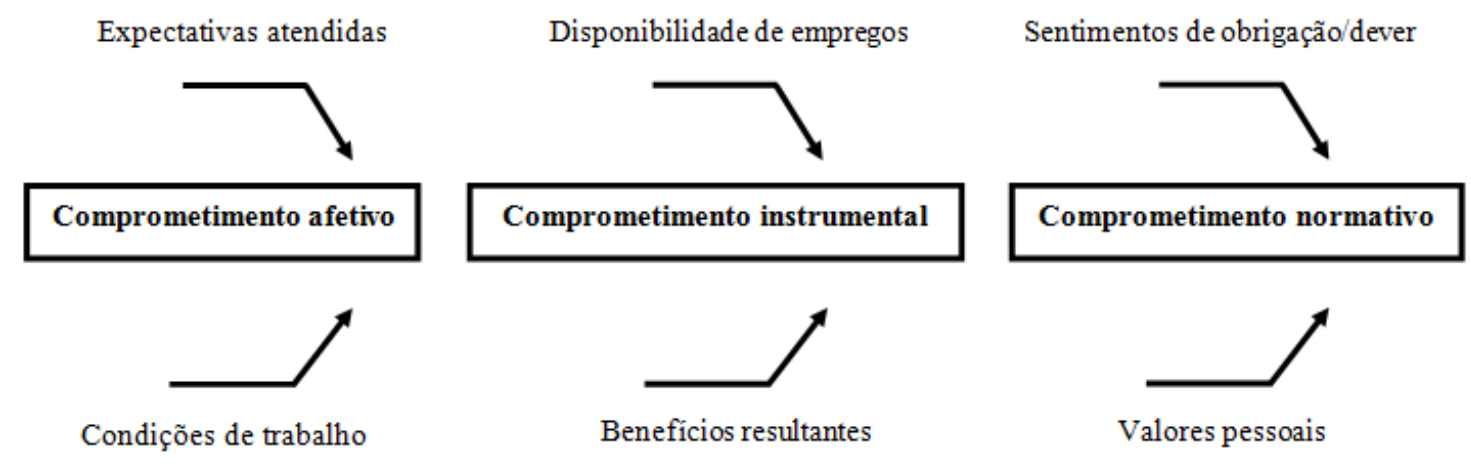

Figura 4 - Antecedentes do comprometimento em suas diferentes dimensões (afetiva, instrumental e normativa) Fonte: Adaptado de Bastos et al. (1997, p. 104).

Uma possível explicação para os baixos escores relacionados ao comprometimento instrumental é a falta de mão-de-obra na região, descrita anteriormente. Segundo publicação em jornal local, desde 2006 existem oportunidades de emprego na cidade em diversas áreas do conhecimento, sendo que muitas destas vagas não exigem qualificação diferenciada. 
Mesmo assim, segundo informações prestadas pelo SINE (Sistema Nacional de Emprego) de Bento Gonçalves, as vagas não conseguem ser supridas (AZEVEDO, 2008).

Neste sentido, levando-se em consideração que o comprometimento instrumental aborda, principalmente, a falta de oportunidades no mercado, justifica-se a constatação dos respondentes terem atribuído menor importância a este fator.

Logo, entende-se o fato das variáveis vinculadas ao comprometimento normativo apresentarem médias entre 4,06 e 5,00 e as variáveis ligadas ao comprometimento instrumental apresentarem os menores escores (entre 2,66 e 3,46).

\subsection{Análise de variância}

Para a verificação das características vinculadas ao perfil dos respondentes, que demonstraram diferenças estatisticamente significativas nas dimensões afetiva, normativa e instrumental do comprometimento organizacional, utilizou-se a técnica de análise de variância (ANOVA). Neste sentido, foram realizados testes de acompanhamento (Testes Post Hoc) com o objetivo de avaliar simultaneamente as estimativas intervalares de segurança das diferenças entre as médias (HAIR et al., 2006).

Neste sentido, estruturou-se a Tabela 5, que apresenta de que maneira variam as médias dos fatores (variáveis dependentes nesta análise) de acordo com os grupos de respondentes. Destaca-se que serão aqui descritos apenas os resultados que se apresentaram significantes (nível de significância p<0,05). 
Mensuração do comprometimento organizacional em redes de indústrias vitivinícolas brasileiras

Tabela 5 - Relações significativas entre fatores do comprometimento organizacional e variáveis

\begin{tabular}{|c|c|c|c|}
\hline Fator & Variável & Significância & Efeito \\
\hline \multirow{4}{*}{$\begin{array}{l}\text { Comprometimento } \\
\text { instrumental }\end{array}$} & $\begin{array}{l}\text { Grau de } \\
\text { instrução }\end{array}$ & 0,003 & $\begin{array}{l}\text { Quando menor o grau de instrução maior o } \\
\text { nível de comprometimento instrumental. }\end{array}$ \\
\hline & Idade & 0,001 & $\begin{array}{l}\text { Quanto maior a idade maior o nível de } \\
\text { comprometimento instrumental. }\end{array}$ \\
\hline & $\begin{array}{l}\text { Tempo de } \\
\text { vínculo de } \\
\text { trabalho com a } \\
\text { empresa }\end{array}$ & 0,014 & $\begin{array}{l}\text { Indivíduos com maior tempo de empresa } \\
\text { apresentam maiores médias nas variáveis } \\
\text { relacionadas ao comprometimento } \\
\text { instrumental. }\end{array}$ \\
\hline & $\begin{array}{l}\text { Área de } \\
\text { atuação na } \\
\text { empresa }\end{array}$ & 0,034 & $\begin{array}{l}\text { Respondentes que atuam na área produtiva } \\
\text { apresentam maiores médias relacionadas } \\
\text { ao comprometimento instrumental. }\end{array}$ \\
\hline \multirow{2}{*}{$\begin{array}{l}\text { Comprometimento } \\
\text { afetivo }\end{array}$} & Município & 0,012 & $\begin{array}{l}\text { Moradores do município de Monte Belo do } \\
\text { Sul apresentam maiores médias de } \\
\text { comprometimento afetivo. }\end{array}$ \\
\hline & Moradia & 0,004 & $\begin{array}{l}\text { Indivíduos que moram em local próprio } \\
\text { apresentam maiores escores de } \\
\text { comprometimento afetivo. }\end{array}$ \\
\hline \multirow{3}{*}{$\begin{array}{l}\text { Comprometimento } \\
\text { normativo }\end{array}$} & Município & 0,003 & $\begin{array}{l}\text { Moradores do município de Monte Belo do } \\
\text { Sul apresentam maiores médias de } \\
\text { comprometimento normativo. }\end{array}$ \\
\hline & $\begin{array}{l}\text { Com quem } \\
\text { você vive }\end{array}$ & 0,040 & $\begin{array}{l}\text { Indivíduos que moram com amigos } \\
\text { possuem maiores escores de } \\
\text { comprometimento normativo. }\end{array}$ \\
\hline & $\begin{array}{l}\text { Membro da } \\
\text { família } \\
\text { fundadora da } \\
\text { empresa }\end{array}$ & 0,015 & $\begin{array}{l}\text { Indivíduos que são membros da família } \\
\text { fundadora da empresa onde trabalham } \\
\text { apresentam maiores médias relacionadas } \\
\text { ao comprometimento normativo. }\end{array}$ \\
\hline
\end{tabular}

Fonte: Dados compilados a partir da pesquisa realizada.

Bastos (1993), ao realizar revisão bibliográfica sobre os antecedentes do comprometimento organizacional, destacou alguns resultados relevantes. Assim, de acordo com o estudo do autor, maiores níveis de comprometimento estão associados à maior idade, maior tempo na organização, maior nível ocupacional e maior remuneração, principalmente quando vinculados à dimensão afetiva. Além disso, o comprometimento é maior entre os 
homens e tende a decrescer quanto maior o nível educacional. Porém, de acordo com os resultados obtidos nesta pesquisa, verificou-se que alguns resultados diferem dos evidenciados por Bastos (1993).

Neste estudo, como observação inicial, a análise de variância apresentou diferenças significativas nas variáveis relacionadas ao grau de instrução, idade, tempo de empresa e área de atuação na empresa, quando vinculadas ao comprometimento instrumental. Neste sentido, considerando-se que o comprometimento instrumental diz respeito aos custos que o indivíduo poderá ter em deixar a organização e à falta de oportunidades no mercado (empregabilidade $)^{4}$, pode-se entender estes resultados.

Inicialmente, conclui-se que quanto menor a escolaridade, menores serão as oportunidades no mercado de trabalho. Outra variável que, em nossa sociedade, influencia as possibilidades de empregabilidade é a idade dos trabalhadores. Camarano (2001), ao realizar um estudo sobre o público idoso no mercado de trabalho brasileiro, afirmou que a educação e a idade se apresentam como fatores expressivos na empregabilidade do público pesquisado. Neste sentido, o aumento da idade pode ter um efeito negativo na empregabilidade, enquanto maiores níveis de educação apresentam um efeito positivo.

Também, cabe aqui destacar que, em geral, trabalhadores das áreas produtivas das empresas apresentam menor escolaridade se comparados aos funcionários de áreas administrativas. Assim, pode entender os resultados apresentados na Tabela 5, a qual evidencia que os trabalhadores das áreas produtivas apresentam maiores médias na dimensão instrumental do comprometimento, corroborando, inclusive, com os resultados apresentados no parágrafo anterior.

Já os trabalhadores com maior tempo de empresa podem ter apresentado maiores médias de comprometimento instrumental por questões de estabilidade no trabalho. Embora esteja emergindo a tendência de, mesmo com um grande de tempo de empresa, o trabalhador agregar novas atividades e competências ao seu dia-a-dia, sabe-se que a permanência por um longo período em uma organização pode surtir um efeito contrário. Assim, colaboradores que permanecem vinculados por longos períodos na mesma organização poderão limitar-se em

\footnotetext{
${ }^{4}$ A empregabilidade pode ser definida como a capacidade dos trabalhadores se atualizarem para manter uma ocupação no mercado. Além disso, este conceito está relacionado com as qualificações requeridas para que o trabalhador, uma vez demitido, tenha capacidade de ocupar e desenvolver um novo trabalho (CARUSO e PERO, 1996).
}

REAd I Porto Alegre - Edição 75 - N 2 - maio/agosto 2013 - p. 351-383 
Mensuração do comprometimento organizacional em redes de indústrias vitivinícolas brasileiras

termos de desenvolvimento de competências, fato que poderá influenciar sua empregabilidade, sendo que este elemento está vinculado ao comprometimento instrumental.

Outro resultado que chama atenção é o fato de trabalhadores que são membros da família fundadora da empresa onde atuam apresentarem maiores médias de comprometimento normativo. Este resultado justifica-se, uma vez que este tipo de comprometimento diz respeito aos sentimentos de obrigação em permanecer na empresa, sendo que este sentimento se estende às pessoas que fazem parte da organização. Assim, as obrigações e a lealdade que se instalam no ambiente familiar acabam se refletindo no ambiente organizacional, justificando, assim, este resultado.

\section{CONSIDERAÇÕES FINAIS}

A obtenção de vantagens competitivas empresariais está relacionada à maneira como o funcionário se envolve e se relaciona com a organização. Com base nesta premissa, buscou-se destacar, no contexto das organizações em rede, o comprometimento organizacional. Para tanto, este estudo avaliou como o comprometimento se manifesta no ambiente interno de organizações em redes, através da mensuração do mesmo em indústrias vitivinícolas localizadas no Vale dos Vinhedos (RS).

Como resultado inicial, foram encontradas as dimensões instrumental, afetiva e normativa do comprometimento organizacional, também destacadas no estudo de Rego et al. (2007).

Além disso, a dimensão afetiva demonstrou maior representatividade, sendo que este resultado pode estar vinculado ao sentimento de orgulho e pertencimento, em relação à empresa, apresentado pelos respondentes. O sentimento de orgulho estaria relacionado ao crescente reconhecimento da atividade vitivinícola e da região onde as vitivinícolas pesquisadas estão localizadas. Já o sentimento de pertencimento pode ser explicado pelo fato de as empresas pesquisadas apresentarem características de empresas familiares que, consequentemente, se refletem na forma de gestão da organização.

Já a dimensão instrumental, que diz respeito a fatores externos sobre os quais o indivíduo tem pouco poder de ação, apresentou baixos escores no contexto pesquisado. Uma possível explicação para este resultado é a falta de mão-de-obra na região onde as empresas 
estudadas se localizam, causando um crescimento na disponibilidade de empregos e, consequentemente, diminuindo a representatividade desta dimensão.

Já na comparação das principais características do perfil dos respondentes com as manifestações do comprometimento organizacional, foram identificadas diferenças significantes em algumas situações.

Assim, observou-se diferenças significativas nas variáveis relacionadas ao grau de instrução, idade, tempo de empresa e área de atuação na empresa, quando vinculadas ao comprometimento instrumental. Este resultado foi explicado considerando-se questões relacionadas à empregabilidade dos respondentes, uma vez que os atores que apresentaram maiores escores nesta dimensão possuem menor escolaridade, maior idade e maior tempo de empresa.

Além disso, trabalhadores que são membros da família fundadora da empresa onde atuam apresentaram maiores médias de comprometimento normativo. Relacionou-se este resultado aos sentimentos de obrigação e lealdade que se instalam no ambiente familiar, refletindo-se no ambiente organizacional.

Assim, verifica-se que o comprometimento está diretamente relacionado à ampliação da consciência do indivíduo (MACÊDO et al., 2005). Este processo ocorre na medida em que o mesmo não se contenta apenas com recompensas financeiras, mas sim com o desejo de conhecer melhor a si mesmo e a empresa, para poder participar efetivamente da vida organizacional.

Este estudo não pretende esgotar a discussão sobre os resultados encontrados. Devido à pluralidade de abordagens vinculadas ao comprometimento organizacional, considera-se relevante elencar algumas sugestões para estudos futuros. Estas sugestões poderão complementar ou, até mesmo, auxiliar no avanço do entendimento da dinâmica que envolve este tema. Assim, sugere-se: (i) novos estudos que explorem quais são os antecedentes do comprometimento organizacional, principalmente em relação às características demográficas do público pesquisado e às práticas de gestão das organizações e (ii) a realização de novos estudos que possibilitem vincular, de forma mais clara e objetiva, as manifestações do comprometimento organizacional e seus reflexos na manutenção ou melhoria dos resultados organizacionais. 
Mensuração do comprometimento organizacional em redes de indústrias vitivinícolas brasileiras

\section{REFERÊNCIAS}

ACADEMIA DO VINHO. Enogastronomia. Disponível em http://www.academiadovinho.com.br/harmonizacao.php. Acesso em: 21 abr. 2010.

ALMEIDA, S. C. M. O Comprometimento Organizacional e o Stress de Papel na Força de Vendas. Dissertação (Mestrado em Gestão Comercial) - Curso de Mestrado Acadêmico em Gestão Comercial da Universidade do Porto, FEP (Faculdade de Economia), Porto, 2009.

APROBELO. Material e informações fornecidos pela associação. Disponível em www.sitedovinhobrasileiro.com.br. Acesso em: 15 jan. 2009.

APROVALE. Material e informações fornecidos pela associação. Disponível em www.valedosvinhedos.com.br. Acesso em: 15 jan. 2009.

AZEVEDO, A. C. Faltam homens. Jornal Serra Nossa, Bento Gonçalves, 12 set. 2008.

BANDEIRA, M. L. et al. As dimensões múltiplas do comprometimento organizacional: um estudo na ECT/MG. Revista de Administração Contemporânea, v. 4, n. 2, p. 133-157, maioagosto, 2000.

BASTOS, A. V. B. Comprometimento organizacional: um balanço dos resultados e desafios que cercam essa tradição de pesquisa. Revista de Administração de Empresas, v. 33, n. 3, p. 52-64, maio-junho, 1993.

BASTOS, A. V. B. Comprometimento no trabalho: os caminhos da pesquisa e os seus desafios teórico-metodológicos. In: TAMAYO, A.; BORGES-ANDRADE, J. E.; CODO, W.: Trabalho, organizações e cultura. Rio de Janeiro: Associação Nacional de Pesquisa e Pósgraduação em Psicologia, 1996, p. 94-109.

BASTOS, A. V. B. et al. Comprometimento organizacional: uma análise do conceito expresso por servidores universitários no cotidiano de trabalho. Revista de Administração Contemporânea, v. 1, n. 2, p. 97-120, maio-agosto, 1997.

BASTOS, A. V. B.; BORGES-ANDRADE, J. E. Comprometimento com o trabalho: padrões em diferentes contextos organizacionais. Revista de Administração de Empresas, v. 42, n. 2, p. 31-41, abril-junho, 2002.

BERNHOEFT. R. Empresa familiar: sucessão profissionalizada ou sobrevivência comprometida. São Paulo: Nobel, 1989. 179 p. 
BRITO, A. P. M. P.; BASTOS, A. V. B. O Shema de "trabalhador comprometido" e gestão do comprometimento: um estudo entre gestores de uma organização petroquímica. Organização \& Sociedade, Salvador, v. 8, n. 22, setembro-dezembro, 2001.

CAMARANO, A. A. O idoso brasileiro no mercado de trabalho. Rio de Janeiro: Instituto de Pesquisa Econômica Aplicada, 2001. 22 p.

CARUSO, L. A. C.; PERO, V. Empregabilidade e reconversão profissional: trabalhadores desligados da indústria. In: ENCONTRO NACIONAL DA ANPOCS (ASSOCIAÇÃO NACIONAL DE PÓS-GRADUAÇÃO E PESQUISA EM CIÊNCIAS SOCIAIS), XX, 1996, Caxambu, Anais... Caxambu: ANPOCS, 1996. p. 70-81.

CHAHAL, H.; MEHTA, S. Antecedents and consequences of organizational citizenship behavior (OCB): a conceptual framework in reference to health care sector. Journal of Services Research, v. 10, n. 2, p. 26-44, october-march, 2011.

CIC BG. Bento Gonçalves: panorama socioeconômico 2009. Bento Gonçalves: Centro da Indústria, Comércio e Serviços de Bento Gonçalves, 2009.

DALCIN, M. S. Vale dos Vinhedos: história, vinho e vida. Bento Gonçalves: MSD Empreendimento culturais; Gráfica Pallotti, 2008. 240 p.

DESSLER, G. Conquistando comprometimento. São Paulo: Makron Books, 1996. 246 p.

DIAS, D. V.; DEL MAESTRO FILHO, A. Valores organizacionais e comprometimento: um estudo em empresas do setor siderúrgico mineiro. In: ENCONTRO DA ANPAD, XXXII, 2008, Rio de Janeiro, Anais... Rio de Janeiro, EnANPAD, 2008. p. 1-16.

FIORITO, J. et al. Organizational commitment, human resource practices, and organizational characteristics. Journal of Managerial Issues. v. XIX, n. 2, p. 186-207, 2007.

HAIR, J. R. Jr. et al. Análise multivariada de dados. 5. ed. Porto Alegre: Bookman, 2006. 593 p.

JAFRI, M. H. Organizational commitment and employee's innovative behavior: a study in retail sector. Journal of Management Research. v. 10, n. 1, p 62-68, april, 2010.

JOO, B. K.; SHIM, J. H. Psychological empowerment and organizational commitment: the moderating effect of organizational learning culture. Human Resource Development International. v. 13, n. 4, p. 425-441, september, 2010. 
Mensuração do comprometimento organizacional em redes de indústrias vitivinícolas brasileiras

LEITE, C. F. F. O comprometimento organizacional na gestão pública: um estudo de caso em uma universidade estadual. In: ENCONTRO DA ANPAD, XXXI, 2007, Rio de Janeiro, Anais... Rio de Janeiro, EnANPAD, 2007. p. 1-16.

MACÊDO, I. I. de et al. Aspectos comportamentais da gestão de pessoas. 5. ed. Rio de Janeiro: Editora FGV, 2005. 148 p.

MARTINS, A. M. S. Programas de qualidade de vida, satisfação no trabalho e comprometimento organizacional. In: ENCONTRO DA ANPAD, XXVII, 2003, Atibaia, Anais... Atibaia, EnANPAD, 2003. p. 1-16.

MEDEIROS, C. A. F. et al. Comprometimento organizacional: o estado da arte da pesquisa no Brasil. RAC eletrônica, v. 7, n. 4, p. 187-209, outubro-dezembro, 2003.

MENDONZA, R. et al. Comprometimento organizacional, fatores estressantes do trabalho e identidade social: um estudo exploratório. Revista de Ciências Humanas e Artes, v. 13, n. 1, p. 92-100, janeiro-julho, 2007.

MEYER, J. P.; ALLEN, N. J. A three-component conceptualization of organizational commitment. Human Resources Management Review. v. 1, n. 1, p. 61-89, 1991.

MOWDAY, R. T. et al. Employee-organizational linkages: the psychology of commitment, absenteeism, and turnover. New York: Academic Press, 1986. 253 p.

NATARAJAN, C. N. K.; NAGAR, D. Effects of service tenure and nature of occupation on organizational commitment and job satisfaction. Journal of Management Research. v. 11, n. 1, p. 59-64, april, 2011.

NAVES, E. M. R.; DELA COLETA, M. F. Cultura e comprometimento organizacional em empresas hoteleiras. RAC eletrônica, edição especial, p. 205-222, 2003.

OSTERMAN, P. Institutional labor economics, the new personnel economics, and internal labor markets: a reconsideration. Industrial and Labor Relations Review, v. 64, n. 4, p. 637653, july, 2011.

PORTER, M. E. Vantagem competitiva: criando e sustentando um desempenho superior. Rio de Janeiro: Campus, 1989. 512 p.

REGO, A.; SOUTO, S. Comprometimento organizacional em organizações autentizóticas: um estudo luso-brasileiro. Revista de Administração de Empresas, v. 44 n. 3, art. 12, julhosetembro, 2004. 
Denise Genari, Kadígia Faccin \& Janaina Macke

REGO, A. et al. Espiritualidade nas organizações e comprometimento organizacional. RAE eletrônica, v. 6, n. 2, art. 12, julho-dezembro, 2007.

SOLDI, R. de M.; ZANELLI, J. C. Comprometimento organizacional de trabalhadores terceirizados e efetivos: um estudo comparativo em uma empresa de telefonia. In:

ENCONTRO DA ANPAD, XXX, 2006, Salvador, Anais... Salvador, EnANPAD, 2006. p. 115.

YILMAZ, E. Organizational commitment and loneliness and life satisfaction levels of school principals. Social Behavior and Personality, v. 36, n. 8, p. 1085-1096, 2008. 